\title{
Integrated Project Delivery Method to Sustainable Construction
}

\author{
Zixiang Chen ${ }^{1,}$, Ping Liu ${ }^{2, b}$, Yunhui Yang ${ }^{3, c^{*}}$ \\ 1,2,3 Kunming Metallurgy College, Kunming, China

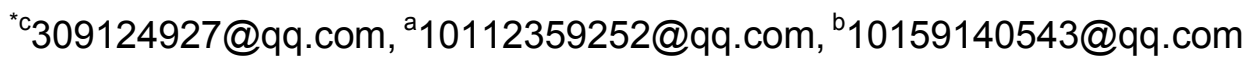

*The Corresponding author

Keywords: Sustainable construction; Integrated project delivery; BIM

\begin{abstract}
Globally, construction utilizes $24 \%$ of raw material extractions; the construction industry uses more materials by weight than any other industry. Currently, the construction industry is undergoing a substantial transition period, as the impacts of buildings are detrimental to the environment. In order to mitigate the negative impacts of the construction industry to the global environment, the construction industry has introduced sustainable building strategies. There are three significant trends that are driving these changes in the industry: building information modeling (BIM), sustainable design and construction, and integrated project delivery system. They are not only re-shaping the construction industry, but also reshaping the construction management and career education. This paper presents the project participants' commitment as the level of the project team's dedication to sustainable, high performance features and predetermined goals in a construction project. And the advantages and challenges of sustainable construction implementation through integrated project delivery method.
\end{abstract}

\section{Introduction}

Sustainable construction has emerged as a guiding paradigm to create a new kind of built environment: "one that meets the needs of humans in the present without limiting the ability of future generalizations to meet their own needs". Sustainable construction refers to a structure and using process that is environmentally responsible and resource-efficient throughout a building's life-cycle. This requires close cooperation of the design team, the architects, the engineers, and the owner at all project stages. The sustainable construction practice expands and complements the classical building design concerns of economy, utility, durability, and comfort.

McGraw- Hill surveys in 2014 confirm that project performance targets can be achieved and exceeded successfully using integrated project delivery method. The project delivery method, chosen by the owner, can affect the achievement of sustainable construction targets (e.g., budget, schedule, and such as the US LEED certification).Researchers have found that the important contributors to the achievement of LEED certification goals include early involvement of key project participants, collaboration, and use of technology. Thus, the adoption and utilization of integrated project delivery method is for sustainable construction projects in order to minimize the impact of buildings on the environment. However, the most utilized project delivery method at present is the traditional Design-Bid-Build.

Sustainable construction in industrialized countries' market continues its momentum, better and more cost-effective strategies to accomplish such as the U.S. LEED certification, which can be formulated on the basis of the smarter technology and process offered by cloud-BIM. Construction industry practitioners are advancing cloud-BIM in the LEED project context and propose a prototype framework of a new business paradigm that implements cloud-BIM solutions in accomplishing LEED Automation. BIM software tools are providing more and more visualizing sustainable design and construction for architectural firms, engineering consultants, building owners and contractors to upgrade building performance. 


\section{Sustainable Construction and Integrated Project Delivery Method}

Integrated project delivery system is an emerging project delivery method that has gained attention for the potential to deliver buildings more effectively (i.e. reaching or exceeding project targets) than previous project delivery methods. A basic principle of integrated project delivery is the reliance on knowledge integration. Integrated project delivery encompasses highly collaborative processes which rely on the collective expertise of the extended project stakeholders (including architects, builders, subcontractors, and owners) contributed throughout the design and construction.

In general, the integrated project delivery method is an approach to building design that seeks to achieve high performance on a wide variety of well-defined environmental and social goals while staying within budgetary and scheduling constraints. Thus, sustainable construction heavily relies upon a multidisciplinary and collaborative team whose members make decisions together based on a shared vision and a holistic understanding of the project, which follows the design through the project life, from pre-design through construction, occupancy and into operation.

\section{Integrated Project Delivery Method and BIM to Sustainable Construction}

With the rapid acceleration BIM into integrated project delivery method, there is a burgeoning market for enabling technology that is aligned to advance integration throughout the building design, construction and management continuum. BIM is now a powerful tool to attain project goals and advantageous in several ways.

A. BIM is an integrated process platform built on coordinated, reliable information about a project from design through construction and into operations. BIM and web-based project management software has created a solid platform for an improved, more efficient means of collaboration between all the parties involved in project delivery and is enabling the trend towards integrative digital collaborations characterized by strategic partners with shared outcomes, risks and gains. Based on BIM tools, integrated project delivery method has enabled cross-functional project teams collaborating on a building's design, construction, and lifecycle management model-based technology as a platform to upgrade and optimize the sustainability and efficiency of the project management to achieve owner outcomes and green strategy. B. By adopting BIM into integrated project delivery method, architects, engineers, contractors and owners can easily create coordinated, digital design information and documentation; use that information to accurately visualize, simulate, and analyze performance, appearance and cost; and reliably deliver the green project faster, more economically and with reduced environmental impact. The BIM models help to enable collaboration between different disciplines by allowing them to visualize the sustainable construction project.

C. Sustainable construction or green building certification like LEED is best suited for fully integrated project teams' collaboration. The team members including architects, builders, subcontractors, and owners have common goals to collaborate throughout the entire project life process, which requires owners, designers, and constructors to collaborate on sustainable project performances and realize cross-disciplinary thinking and skills. The BIM models ensure accuracy of design by detecting design problems before construction occurred, which saved time and money. For example, off-site prefabrication saved the projects time and material waste. 


\section{Green Building Certification Achieving through Integrated Project Delivery Method}

Sustainable construction strategies will determine how to incorporate the green building certification requirements from the design to operation. The architect, engineering consultants, landscape architect, and interior designers will ensure that all sustainable design features are well documented in the specifications and drawings, evaluate points available through the current design and assign responsibility to individual consultants to complete credit documentation such as the US LEED.

A. Early involvement of the project participants have the greatest control of the costs of sustainable construction project; making more informed choices in the design phase can reduce the final costs; contractual agreements that increase the exchange of construction and operations knowledge during the design phase can be utilized. Furthermore, early involvement of owners can keep project costs low with competitive bidding compromise design quality and craftsmanship, as a result, it will optimize more long term costs due to greater operations and maintenance expenses.

B. Reviewing all drawings for green certification compliance will ensure the owner's objectives and design intent continuing to be achieved in the construction documents, such as energy requirements, daylight factors, water use calculations, and all prerequisites are confirmed by the green building certification requirements. For example, achieving a LEED rating level, or reducing environmental impacts from wastewater, solid waste by a certain percentage below the standard practice.

C. Considering green certification requirements when it is developing the construction sequencing plan and specifications. For example, demolition or excavation will occur while construction documents are being completed, which can have an impact on green certification requirements for erosion and sedimentation control and demolition waste management; and develop terms of responsibility and requirements for the contractor and sub-trades to collect certification documentation (i.e., material safety data sheets showing emission levels of products).

D. 4D modeling construction visualization and prefabrication techniques blur the distinction between design and production. Design simulation sensibility regarding constructability shifts have given rise to extensive pre-fabrication, mass customization, and factory-produced building components. Digitally fabricated building components further reduce the pressure on field construction productivity. Most notably is the improvement in project planning of sustainable projects. Sustainable construction is best built when the owner is fully committed to achieve a desired certification level. This allows projects to be planned and designed in a more collaborative and efficient multidisciplinary manner through integrated project delivery method.

E. Traditional project phases will be adjusted and refined to accommodate an integrated project team and their project participation by using BIM models through integrated project delivery system. A more thorough sustainable construction design rigorously analyzed and imbued with construction knowledge by using 4D visualizations will result in a shorter documentation phase, reducing poor design decisions, result in fewer variations and change orders, and less rework during design and construction, which will reduce the level of guesswork and inefficiency in pre-construction estimating in the BIM process; and will improve procurement and project scheduling through cost modeling techniques; and will reduce the number of field coordination errors by integrating the design models of the major design disciplines and using clash detection software to facilitate interdisciplinary design coordination, solving coordination issues virtually rather than in the field, so as to accelerate sustainable construction.

F. Finally, life-cycle costing is the ability to model a building's financial performance over its life cycle by using BIM models into integrated project delivery method, which can reduce first costs, 
and reduce cost impacts of coordination errors, incorrect fabrication, and improper installation and carrying costs by optimizing project schedules that will result in faster construction, and reduce the use of overtime labor and premium charges for recouping project schedule lost to these unnecessary errors; which can also justify measures that may require greater initial capital investment, but can substantially lower operational costs over time.

\section{BIM Based Integrated Project Delivery Method Advantages on Sustainable Construction}

BIM tools provides platforms for integrated processes on coordinated reliable information, and allow sustainable project teams to visualize construction plans, identify construction sequences, and improve communication within the team. By adopting BIM into integrated project delivery method, owners are becoming more definitive in their demands for reliable results in the design to construction process of sustainable construction and actual performance in the post-occupancy stage.

A. The most important characteristic of integrated project delivery method is a broad collaborative team relates to inclusiveness and collaboration. Ideally, the team includes all relevant disciplines and stakeholders who remain involved from start to finish. A sustainable project is more likely to be successful if its members trust each other and are able to cooperate. A broad interdisciplinary team representing all necessary skills, knowledge, and perspectives is essential to co-operate and interact with each other for a clear vision accompanied by well-defined goals and objectives.

B. Probably the most critical element of integrated project delivery method is promoting effective communication. Open and continuous lines of communication are essential throughout the sustainable project life, both during and between meetings. Effective communication of interdisciplinary team throughout the sustainable project process can foster an atmosphere of lasting respect and trust, and imply that the whole is greater than the sum of the individual parts. Transparent methods of communication will build trust and give participants a greater sense of ownership over the integrated project delivery method process, reduce conflicts and allow the sustainable project to benefit from each individual's unique contribution.

C. Integrated project delivery method approach includes feedback mechanisms to evaluate all decisions. An iterative of integrated project delivery method process ensures that decisions reflect the broader team's collective knowledge, that interactions between different elements are considered, and that solutions go through the steps needed for optimization to the sustainable building. Regular feedback loops can keep the team engaged and produce small successes, which reinforce the effectiveness of the process. Lessons learned from the successes and failures of past projects are used to improve sustainable building practices for future endeavors.

\section{Conclusion}

Sustainable construction is becoming an increasingly widespread worldwide initiative. By using BIM models it becomes apparent that integrated project delivery method provides many inherent green advantages over conventional construction methods, and provides more assurance that project performance targets will be met or exceeded. Previous study has indicated that integrating the sustainable project's objectives during programming of design and construction eventually results in reducing delays, costs, and rework on the project. As above outlined, construction industry companies are facing competitive pressure and challenges to produce cost-effective, high quality designs and finished sustainable construction projects. Though integrated project delivery method is 
gaining recognition in the building industry, it is not commonly used yet. As the building industry becomes more integrated and greener, the education of future professionals will no doubt follow suite with altered curricula that reflects the increasingly large footprint of integrating design and construction. It will be a significant challenge for institutions that are not structured in a manner conducive to this requirement, especially for the developing countries such as China.

\section{References}

[1] World Green Buiding Trend, Smart Market Report (2014), McGraw-Hill Construction.

[2] Alarcón, L. F., \& Mesa, H. H. (2014). A conceptual framework to model the performance of project delivery systems. eWork and eBusiness in Architecture, Engineering, and Construction.

[3] Young, N., Jones, S., Bernstein, H., and Gudgel, J. (2009). The Business Value of BIM: Getting Building Information Modeling to the Bottom Line.

[4] Bendewald, M., Franta, L., \& Pradhan, A. (2010). Autodesk AEC headquarters and integrated project delivery. Retrieved from http://www.rmi.org/Knowledge-Center/Library/2010-

16_AutodeskCaseStudy

[5] Atul Khanzode, An Integrated, Virtual Design and Construction and Lean (IVL) Method for Coordination of MEP, CIFE Technical Report \#TR187,February 2010, STANFORD UNIVERSITY.

[6] CMHC. 2005. Research Highlights: Technical Series 04-102. Calgary Integrated Design and Sustainable, Affordable Housing Charrette. Ottawa: CMHC.

[7] Aberdeen Group, Inc. 2002. Quantifying the Vision: Building the Case for Project Collaboration in the Construction Industry. White Paper. Boston, MA: Aberdeen Group.

[8] Kibert, C. J. (2008). Sustainable construction: Green building design and delivery (Second Edi). Hoboken: John Wiley \& Sons, Inc. 